\title{
Pabrikasi Magnet MnZn Ferit dan Barium Ferit dari Limbah Pengelasan
}

\section{Fabrication of MnZn Ferrite and Barium Ferrite using Welding Waste}

\author{
Ardita Septiani* dan Novrita Idayanti \\ Pusat Penelitian Elektronika dan Telekomunikasi, Lembaga Ilmu Pengetahuan Indonesia. \\ Komp LIPI Gd 20, Jl Sangkuriang 21/54D, Bandung 40135, Indonesia
}

\begin{abstract}
Abstrak
Pembuatan magnet lunak MnZn ferit dan magnet keras barium ferit telah dilakukan menggunakan bahan baku utama limbah pengelasan. Limbah pengelasan yang digunakan merupakan limbah dengan komposisi utama $\mathrm{Fe}$ dan $\mathrm{O}$ dengan $\mathrm{Al}$ dan Bi sebagai pengotor. Magnet dipabrikasi menggunakan metode metalurgi serbuk, yang diawali dengan penggilingan selama 6 jam untuk mendapatkan serbuk, dilanjutkan dengan pemanggangan pada $560{ }^{\circ} \mathrm{C}$ selama 1 jam untuk mendapatkan fasa hematit. Karakterisasi XRD ( $x$-ray diffraction) menggunakan analisa Rietveld menunjukkan hematit $73,4 \%$ berat telah terbentuk setelah pemanggangan dengan fasa magnetik sebesar $26,6 \%$ berat. Serbuk setelah pemanggangan digunakan sebagai bahan baku magnet ferit dengan ditambahkan senyawa penyusun kation dan aditif. Perhitungan stoikiometri bahan baku yang digunakan pada penelitian ini didasarkan pada rumus kimia $\mathrm{Mn}_{0,8} \mathrm{Zn}_{0,2} \mathrm{Fe}_{2} \mathrm{O}_{4}$ dan $\mathrm{BaFe}_{12} \mathrm{O}_{19}$. Melalui karakterisasi menggunakan Permagraph, pembuatan magnet menggunakan limbah pengelasan didapatkan sifat magnetik untuk MnZn ferit adalah induksi remanen 0,83 $\mathrm{kG}$ dengan koersifitas $0,084 \mathrm{kOe}$ dan untuk barium ferit memiliki induksi remanen 1,22 $\mathrm{kG}$ dengan koersifitas $2,996 \mathrm{kOe}$.
\end{abstract}

Kata kunci: $M n Z n$ ferit, barium ferit, limbah pengelasan.

\section{Abstract}

Fabrication of soft magnet MnZn ferrite and hard magnet barium ferrite has been done using welding wastes as raw materials. The welding wastes that used in this study constitute mainly $\mathrm{Fe}$ and $\mathrm{O}$ with $\mathrm{Al}$ and Bi as impurities. Powder metallurgy is employed to produce these magnets that started with milling the welding wastes for 6 hours to attain powders and followed by roasting it at $560{ }^{\circ} \mathrm{C}$ for 1 hour to obtain hematite phases. Through XRD (x-ray diffraction), it is found that hematite of $73.4 \%$ has been formed while magnetite of $26.6 \%$ of total mass is still present. Roasted powders are then used as raw materials for ferrite magnets. Stoichiometry calculation for raw materials used for this study is based on formulae of $\mathrm{Mn}_{0.8} \mathrm{Zn}_{0.2} \mathrm{Fe}_{2} \mathrm{O}_{4}$ and $\mathrm{BaFe}_{12} \mathrm{O}_{19}$. Parmagraph characterization shows that for the MnZn ferrite and barium ferrite fabricated using welding wastes as raw materials have remanent induction of 0.83 and $1.22 \mathrm{kG}$, coercivity of 0.084 and $2.996 \mathrm{kOe}$ respectively.

Keywords: MnZn ferrite, barium ferrite, welding waste.

\section{Pendahuluan}

Magnet ferit yaitu magnet dengan rumus kimia $\mathrm{M} . \mathrm{Fe}_{2} \mathrm{O}$, secara umum memiliki sifat tahan korosi, stabilitas kimia yang baik, temperatur Curie yang tinggi, serta dapat dipabrikasi menjadi magnet keras dan magnet lunak bergantung dengan pengaturan komposisi M. Penggunaan unsur Mn dan $\mathrm{Zn}$ membuat struktur kristal memiliki derajat anisotropi yang rendah dengan koersifitas rendah. Magnet lunak berdasar ferit memiliki resistivitas listrik yang tinggi sehingga meminimalisir kehilangan energi akibat Eddy current [1]. Pada $\mathrm{Mn}_{\mathrm{x}} \mathrm{Zn}_{1-\mathrm{x}} \mathrm{Fe}_{2} \mathrm{O}_{4}$, konsentrasi $\mathrm{Mn}$ akan menurunkan koersifitas dan meningkatkan nilai magnetisasi maksimum [2]. Ba dan Sr membuat magnet memiliki derajat anisotropi yang tinggi dengan koersifitas yang lebih tinggi. Medan magnet yang dihasilkan oleh

\footnotetext{
* Corresponding Author.

Email: ardi012@lipi.go.id

Received: April 13,2015; Revised: April 24, 2015

Accepted: April 30,2015

Published: June 30, 2015

(c) 2015 PPET - LIPI

doi : 10.14203/jet.v15.14-17
}

magnet ferit keras lebih rendah dibanding dengan magnet logam tanah jarang, namun stabilitas kimia yang baik dan rasio harga per performa yang tinggi membuat magnet ferit banyak diaplikasikan. Perbedaan kuat medan magnet ferit keras dengan magnet logam tanah jarang semakin dipersempit dengan ditemukannya ferit berdasar LaCo pada tahun 1997 [3].

Pembagian magnet menjadi lunak dan keras didasarkan pada nilai induksi remanen dan koersifitas [4]. Magnet lunak memiliki nilai induksi remanen dan koersifitas mendekati nol atau sangat rendah. Magnet lunak digunakan dengan cara memberi arus untuk memagnetisasi material, koersifitas yang mendekati nol tersebut akan berefek pada kehilangan energi per siklus (magnetisasi dan demagnetisasi) minimum. Magnet keras memiliki nilai induksi remanen dan koersifitas yang sama-sama besar. Perbedaan antara magnet keras dan lunak juga dapat dilihat pada bentuk kurva histeresis, magnet keras akan menghasilkan luas area kurva yang jauh lebih besar dibandingkan dengan magnet lunak seperti yang ditunjukkan pada Gambar 1. 
Dapat dilihat magnet keras memiliki $\mathrm{H}$ yang jauh lebih lebar dibandingkan dengan magnet lunak yang menunjukkan koersifitas magnet keras lebih besar. Namun, selain yang terpampang pada contoh kurva histerisis Gambar 1, nilai induksi maksimum (pada sumbu B) dari magnet lunak dapat lebih besar dibandingkan dengan magnet keras.

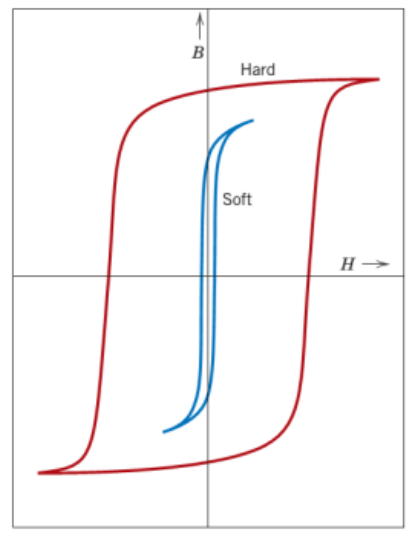

Gambar 1. Kurva Histeresis Magnet Lunak (Soft) dan Magnet Keras (Hard) [5].

Parameter sifat magnetik yang paling menentukan dari magnet keras adalah induksi remanen, karena penggunaan magnet keras tidak menggunakan arus listrik ketika diaplikasikan (atau nilai $\mathrm{H} \mathrm{nol).} \mathrm{Sedangkan}$ magnet lunak menggunakan arus listrik pada penggunaanya, sehingga magnetisasi maksimum atau induksi maksimum lebih mempengaruhi performa magnet daripada induksi remanen.

Pabrikasi magnet ferit secara komersial menggunakan metode metalurgi serbuk dengan bahan baku utama hematit $\left(\alpha \quad \mathrm{Fe}_{2} \mathrm{O}_{3}\right)$, dengan tambahan senyawa penyusun kation dan aditif. Metode yang digunakan untuk membuat ferit sudah sangat berkembang khususnya metode dalam pabrikasi menggunakan partikel nano seperti co-precipitation [6], mechanical alloying [7], sonochemical reaction [8], microwave plasma [9], metode hidrotermal [10], metode sol-gel [11], dan metode emulsi mikro [12].

Limbah pengelasan memiliki unsur utama Fe dalam bentuk oksida, di mana Fe teroksidasi pada suhu tinggi ketika proses pengelasan. Konten oksida Fe yang tinggi ini memiliki potensi untuk dijadikan bahan baku pembuatan magnet. Tingkat oksidasi limbah pengelasan harus diketahui untuk menentukan apakah dibutuhkan oksidasi lebih lanjut. Penelitian mengenai limbah pengelasan sebagai bahan baku pembuatan magnet belum banyak dilakukan. Limbah pengelasan sendiri memiliki banyak jenis sesuai dengan metode las dan kawat las yang digunakan, sehingga komposisi penyusunnya pun bervariasi.

Tujuan dari penelitian ini adalah untuk mengetahui sifat magnetik dari magnet keras dan magnet lunak yang dihasilkan dari pabrikasi menggunakan limbah pengelasan sebagai bahan baku dengan pemanggangan sebagai persiapan bahan baku.

\section{Material dan Metode}

Penelitian ini menggunakan metode metalurgi serbuk untuk membuat magnet. Pembuatan magnet diawali dengan penggilingan limbah pengelasan selama 6 jam untuk menghaluskannya menjadi serbuk. Serbuk hasil penggilingan lalu di karakterisasi menggunakan SEM - EDS (scanning electron microscopy - energy dispersive spectrometry) untuk mengetahui unsur yang terdapat pada limbah pengelasan. Serbuk limbah pengelasan dipanggang pada temperatur $560{ }^{\circ} \mathrm{C}$ selama 1 jam dengan tambahan oksigen sebesar $3 \mathrm{~mL} / \mathrm{menit}$ untuk mengoksidasi serbuk. Karakterisasi XRD ( $x$-ray diffraction) dan analisis Rietveld dilakukan untuk mengetahui jenis fase besi oksida yang terbentuk dan perbandingan massanya, sebelum dan setelah pemanggangan.

Perhitungan stoikiometri bahan baku yang digunakan pada penelitian ini didasarkan pada rumus kimia $\mathrm{Mn}_{0,8} \mathrm{Zn}_{0,2} \mathrm{Fe}_{2} \mathrm{O}_{4}$ dan $\mathrm{BaFe}_{12} \mathrm{O}_{19}$. Untuk $\mathrm{MnZn}$ ferit, pencampuran dilakukan dengan menambahkan $\mathrm{MnCO}_{3}$ dan $\mathrm{ZnO}$, sedangkan untuk barium ferit ditambahkan senyawa $\mathrm{BaCO}_{3}$. Pencampuran dilakukan melalui penggilingan menggunakan ball mill selama 8 jam dengan media alkohol. Setelah dikeringkan, kedua campuran ini dikalsinasi pada suhu $1200{ }^{\circ} \mathrm{C}$ selama 3 jam. Selanjutnya dilakukan penambahan aditif $\mathrm{CaO}$ dan $\mathrm{SiO}_{2}$ melalui penggilingan 16 jam dengan penambahan PVA (polivinil alkohol) pada 8 jam terakhir penggilingan. Setelah kering, kompaksi dilakukan dengan menggunakan beban $1500 \mathrm{~kg} / \mathrm{cm}^{2}$. Proses sintering dilakukan pada temperatur $1250{ }^{\circ} \mathrm{C}$ selama 1 jam. Karakterisasi sifat magnetik dilakukan menggunakan alat Permagraph untuk mendapatkan nilai induksi remanen dan koersifitas.

\section{Hasil dan Pembahasan}

Gambar 2 merupakan gambar SEM area pasir besi yang dideteksi oleh EDX, dengan komposisi hasil pada Tabel 1. Penyusun utama dari limbah pengelasan adalah unsur $\mathrm{Fe}, \mathrm{O}$, Al, dan $\mathrm{Bi}$. Kolom 3 pada Tabel 1 menampilkan error atau kemungkinan kesalahan pengukuran Bi sebesar 3,52\% melebihi presentase yang terukur yaitu 2,25\%, menunjukkan keberadaan unsur $\mathrm{Bi}$ memiliki derajat ketidakpastian yang tinggi. Al merupakan unsur yang terdapat pada jenis limbah pengelasan yang digunakan. Dapat dilihat konten dari Fe sebesar $68,36 \%$ berat dengan unsur $\mathrm{O}$ sebesar 24,34\% menunjukkan keberadaan $\mathrm{Fe}$ pada limbah pengelasan berada dalam bentuk oksida.

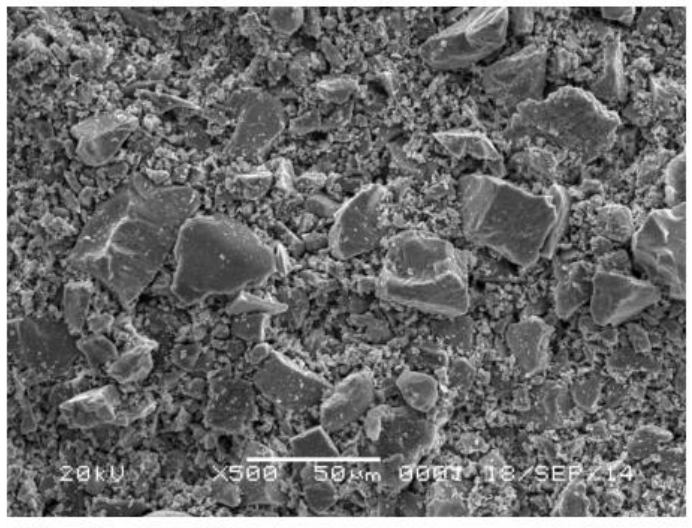

Limbah Las SEM 500x eds ox

Gambar 2. Area Pengujian EDS Limbah Pengelasan. 
TABEL 1

KOMPOSISI LIMBAH PENGELASAN

\begin{tabular}{|c|c|c|}
\hline Unsur & Komposisi (\% berat) & Error $(\%$ berat $)$ \\
\hline $\mathrm{Fe}$ & 68,36 & 2,85 \\
\hline $\mathrm{O}$ & 24,34 & - \\
\hline $\mathrm{Al}$ & 5,05 & 1,96 \\
\hline $\mathrm{Bi}$ & 2.25 & 3,52 \\
\hline
\end{tabular}

Pada Gambar 3 dapat dilihat perubahan puncak (peak) pada sebelum dan sesudah pemanggangan. Kurva XRD menunjukkan bahwa $\mathrm{Fe}$ pada limbah pengelasan terdapat dalam bentuk oksida. Puncakpuncak hematit tidak terlihat, hanya fase magnetit $\left(\mathrm{Fe}_{3} \mathrm{O}_{4}\right)$ b dan wustite $(\mathrm{FeO})$ a yang terlihat. Setelah dilakukan pemanggangan, dapat diamati puncak dari hematit $\left(\alpha \mathrm{Fe}_{2} \mathrm{O}_{3}\right) \mathrm{c}$ dengan masih ada puncak-puncak magnetit $b$.

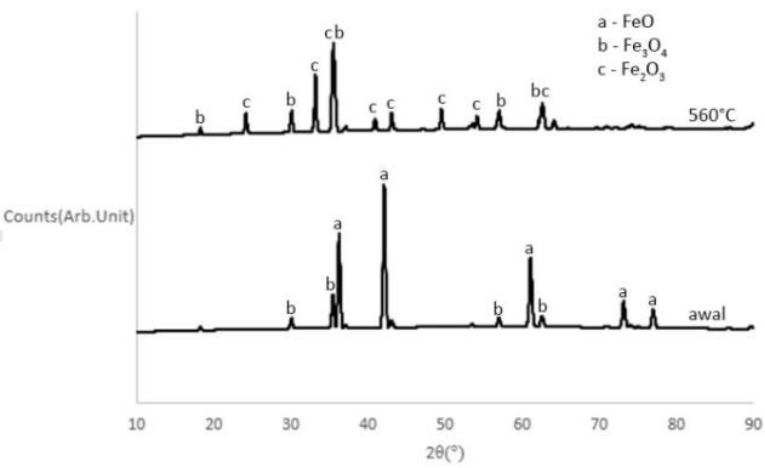

Gambar 3. Kurva XRD Sebelum dan Sesudah Pemanggangan.

TABEL 2

HASIL ANALISIS RIETVELd SEBELUM DAN SESUdAH PEMANGGANGAN

\begin{tabular}{|l|c|c|c|}
\hline \multirow{2}{*}{} & \multicolumn{4}{|c|}{ Persentase Berat (\%) } \\
\cline { 2 - 4 } & $\mathbf{F e O}$ & $\mathbf{F e}_{\mathbf{3}} \mathbf{O}_{\mathbf{4}}$ & $\mathbf{F e}_{\mathbf{2}} \mathbf{O}_{\mathbf{3}}$ \\
\hline Limbah awal & 82 & 18 & - \\
\hline Setelah Pemanggangan & - & 26,6 & 73,4 \\
\hline
\end{tabular}

Unsur oksigen yang terukur oleh EDS sebagian besar merupakan anion dari besi oksida yang juga ditunjukkan dengan hasil XRD. Pada kurva XRD, senyawa yang melibatkan $\mathrm{Al}$ berada dalam jumlah yang kecil sehingga kemungkinan tersamar pada background noise pada kurva XRD. Oleh karena itu, perhitungan pada Tabel 2 didasarkan pada puncak yang terdeteksi XRD sehingga pengotor $\mathrm{Al}$ dan $\mathrm{Bi}$ tidak masuk ke dalam perhitungan.

Analisis Rietveld pada Tabel 2 menunjukkan limbah pengelasan memiliki senyawa utama wustit (FeO) sebesar $82 \%$ dengan presentasi magnetit $18 \%$ dari total berat. Hal ini menunjukkan dibutuhkan dua proses oksidasi yaitu untuk mengoksidasi $\mathrm{FeO}$ menjadi $\mathrm{Fe}_{3} \mathrm{O}_{4}$ lalu menjadi $\mathrm{Fe}_{2} \mathrm{O}_{3}$.

Penggunaan temperatur dan waktu oksidasi yang digunakan masih belum dapat mengoksidasi magnetit dan wustit secara penuh. Oksidasi wustit dan magnetit merupakan reaksi yang terkontrol oleh difusi dari oksigen dalam bentuk gas, dan laju difusi akan diperlambat oleh meningkatnya ketebalan dari lapisan yang teroksidasi [13]. Oksidasi pada temperatur $560{ }^{\circ} \mathrm{C}$ selama 1 jam sudah dapat menghasilkan hematit sebesar $73,4 \%$, dibutuhkan waktu tambahan untuk menghasilkan hematit dengan kadar mendekati 100\%.
Proses oksidasi pada besi menciptakan struktur lapisan dengan bilangan oksida tertinggi berada di permukaan dan bilangan oksidasi terendah berada di tengah [14]. Hal ini berkaitan dengan difusi oksigen yang berasal dari atmosfer atau gas lalu berpenetrasi ke permukaan dan berdifusi menuju ke tengah. Pada hasil XRD, hal ini terlihat pada keberadaan fasa, pada limbah pengelasan terdapat $\mathrm{FeO}$ dengan bilangan oksidasi $\mathrm{Fe}^{2+}$ dan $\mathrm{Fe}_{3} \mathrm{O}_{4}$ dengan bilangan oksidasi $\mathrm{Fe}^{2+}$ dan $\mathrm{Fe}^{3+}$. Setelah pemanggangan terdapat dua lapisan yaitu $\mathrm{Fe}_{3} \mathrm{O}_{4}$ dan $\mathrm{Fe}_{2} \mathrm{O}_{3}$ dengan bilangan oksidasi $\mathrm{Fe}^{3+}$. Jika dilihat dari rasio fasa, $\mathrm{FeO}$ yang berada pada bagian yang lebih dalam sudah teroksidasi menjadi $\mathrm{Fe}_{3} \mathrm{O}_{4}$ dan $\mathrm{Fe}_{2} \mathrm{O}_{3}$, namun kemungkinan magnetit yang berada pada bagian dalam tidak teroksidasi lebih lanjut. Keberadaan fasa magnetit ini dapat mempengaruhi reaksi pembentukan senyawa magnetik.

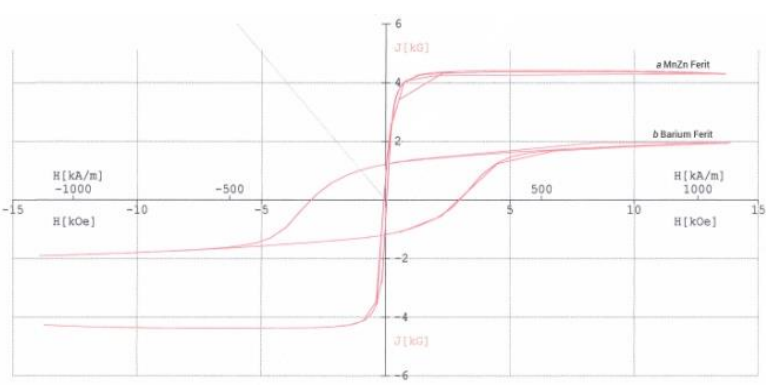

Gambar 4. Kurva Histeresis dari MnZn Ferit dan Barium Ferit dari Limbah Pengelasan.

TABEL 3

SIFAT MAGNETIK DARI MNZN FERIT DAN BARIUM FERIT DARI LIMBAH PENGELASAN

\begin{tabular}{|l|c|c|}
\hline \multicolumn{3}{|c|}{ PENGELASAN } \\
\hline MnZn ferit & $\begin{array}{c}\text { Induksi } \\
\text { Remanen }(\mathbf{k G})\end{array}$ & $\begin{array}{c}\text { Koersifitas } \\
\text { (kOe) }\end{array}$ \\
\hline Barium ferit & 0,83 & 0,084 \\
\hline
\end{tabular}

Pada Gambar 4 terdapat 2 kurva yaitu kurva a yang merupakan kurva histeresis dari MnZn ferit dan kurva $b$ yaitu kurva histeresis dari barium ferit. Kurva a MnZn ferit yang merupakan magnet lunak memiliki bentuk yang ramping dan memiliki area di dalam kurva yang sempit sedangkan kurva $b$ menunjukkan area dalam kurva yang luas yang merupakan ciri magnet keras. Gambar 4 menunjukkan kurva histeresis yang menyerupai Gambar 1.

Koersifitas dari barium ferit $=2,996 \mathrm{kOe}$, lebih tinggi dibandingkan koersifitas MnZn ferit $=0,084 \mathrm{kOe}$, sesuai dengan kategori magnet keras yang memiliki koersifitas yang besar dan magnet lunak yang memiliki koersifitas mendekati nol. Dari kurva a dapat dilihat bahwa induksi maksimum dari MnZn ferit sekitar $4 \mathrm{kG}$ pada $\mathrm{H}=0,550 \mathrm{kOe}$. Induksi remanen dari barium ferit yang dihasilkan sebesar 1,22 kG masih lebih rendah namun mendekati, dibanding dengan magnet ferit komersial dengan induksi remanen 1,725 - 4,3 kG [15].

Riset lebih lanjut dibutuhkan untuk meningkatkan sifat magnetik dari magnet yang dibuat dari limbah pengelasan. Konten hematit perlu ditingkatkan lebih tinggi dari yang dihasilkan pada penelitian kali ini, serta perlu diketahui pengaruh $\mathrm{Al}$ terhadap sifat magnetik dari MnZn ferit dan barium ferit. 


\section{KESIMPULAN}

Pabrikasi magnet dari limbah pengelasan menggunakan metode metalurgi serbuk didahului dengan oksidasi limbah pengelasan pada suhu $560{ }^{\circ} \mathrm{C}$ selama 1 jam mengasilkan induksi remanen dan koersifitas dari magnet $\mathrm{MnZn}$ ferit masing-masing sebesar $0,83 \mathrm{kG}$ dan $0,084 \mathrm{kOe}$, sedangkan untuk barium ferit masing-masing sebesar $1,22 \mathrm{kG}$ dan 2,996 kOe. Oksidasi limbah pada suhu $560{ }^{\circ} \mathrm{C}$ selama 1 jam masih tidak dapat mengoksidasi penuh wustit dan magnetit menjadi hematit, hematit yang terbentuk sebesar $73,4 \%$ dengan magnetit sebesar $26,6 \%$.

\section{UCAPAN TERIMA KASIH}

Penulis mengucapkan terima kasih kepada PPET LIPI atas fasilitas yang telah digunakan dalam penelitian ini dan DIPA Tematik atas pendanaan penelitian.

\section{Daftar Pustaka}

[1] S. Kanazawa, N. Takahashi, and T. Kubo, "Measurement and analysis of AC loss of NdFeB sintered magnet", Electrical Engineering in Japan, vol. 154 (4), pp. 8-15, 2006.

[2] J. G. Lee, J. H. Kim, and K. P. Chae, "Crystallographic and magnetic properties of Zn-Mn ferrite", Journal of the Korean Physical Society, vol. 49 (2), pp. 604-607, 2006.

[3] The Ceramic Society of Japan, "Automobile engines and car electronics", in Advanced Ceramic Technologies and Product, 1st ed, Y. Imanaka, Tokyo, Japan: Springer Japan, 2012, p. 301.

[4] P. S. Neelakanta, Handbook of Electromagnetic Materials. Monolithic and Composite Versions and Their Applications, 1st ed., Florida, United States of America: CRC Press, 1995, p. 347.
[5] W. D. Callister Jr., Material Science and Engineering: An Introduction, 7th ed., United States of America: John Wiley \& Sons, Inc., 2007, w39.

[6] A. Ataie, S. Heshmati-Manesh, and H. Kazempour, "Synthesis of barium hexaferrite by the co-precipitation method using acetate precursor", Journal of Material Science, vol. 37 (10), pp. 2125-2128, 2002.

[7] J. Ding, P. G. McCormick, and R. Street, "Formation of spinel Mn-ferrite during mechanical alloying", Journal of Magnetism and Magnetic Materials, vol. 171(3), pp. 309-314, 1997.

[8] K. V. P. M. Shafi, A. Gedanken, R. Prozorov, and J. Balogh, "Sonochemical preparation and size-dependent properties of nanostructured $\mathrm{CoFe}_{2} \mathrm{O}_{4}$ particles", Chemistry of Materials, vol. 10 (11), pp. 3445-3450, 1998.

[9] Y. P. Fu, K. Y. Pan, and C. H. Lin, "Microwave-induced combustion synthesis of $\mathrm{Ni0} .25 \mathrm{Cu} 0.25 . \mathrm{Zn} 0.5$ ferrite powders and their characterizations", Material Letters, vol. 57 (2), pp. 291-296, 2002.

[10] K. Nejati and R. Zabihi, "Preparation and magnetic properties of nano size nickel ferrite particles using hydrothermal method", Chemistry Central Journal, vol. 6 (no. 23), pp. 1-6, 2012.

[11] Y. Y. Meng, M. H. He, Q. Zeng, D. L. Jiao, S. Shukla, and R. V Ramanujan, Z. W. Liu, "Synthesis of barium ferrite ultrafine powders by a sol-gel combustion method using glycine gels", Journal of Alloys and Compounds, vol. 583, pp. 220-225, 2014.

[12] A. Kosak, D. Makovec, A. Znidarsic, and M. Drofenik, "Preparation of MnZn-ferrite with microemulsion technique, Journal of the European Ceramic Society, vol. 24 (6), pp. 959962, 2004.

[13] E. R. Monazam, R. W. Breault, and R. Siriwardane, "Kinetics of magnetite $\left(\mathrm{Fe}_{3} \mathrm{O}_{4}\right)$ oxidation to hematite $\left(\mathrm{Fe}_{2} \mathrm{O}_{3}\right)$ in air for chemical looping combustion", Industrial \& Engineering Chemistry Research, vol. 53 (34), pp. 13320-13328, 2014.

[14] R. Y. Chen and W. Y. D. Yuen, "Oxide-scale structures formed on commercial hot-rolled steel strip and their formation mechanism", Oxidation of Metals, vol. 56, pp. 89-118, 2001.

[15] (2015). The integrated magnetics website. [Online]. Available: http://www.intemag.com/magnetic_properties.html\#Ferrite_(Cer amic)_-_Magnetic_Properties. 